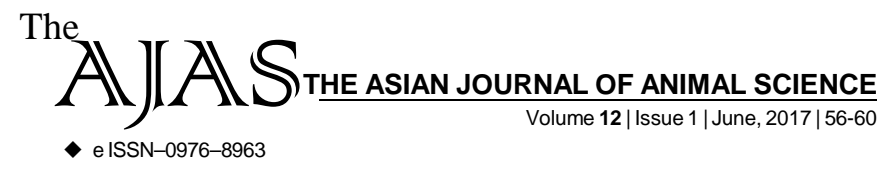

DOI : 10.15740/HAS/TAJAS/12.1/56-60

\title{
Response of post larvae of Penaeus monodon (Fabricius, 1798) to varying temperatures
}

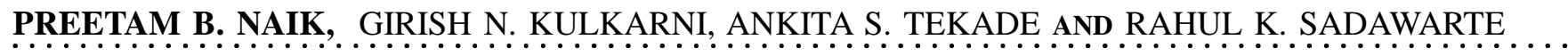
ABSTRACT...... Temperature is a key environmental variable mainly influencing the survival and biological responses of the organisms. In order to understand the influence of temperature on survival and growth of post- larvae (PL 50) of tiger shrimp, Penaeus monodon, static bioassays as per standard methodology were undertaken. The $96 \mathrm{~h} \mathrm{LT}_{50}$ value was found to be $32.2{ }^{\circ} \mathrm{C}$. Rates of oxygen consumption were affected by temperature with direct relationship. The oxygen consumption rate of post-larva was the lowest $\left(0.31 \mathrm{mg} \mathrm{lit}^{-1}\right)$ at $28^{\circ} \mathrm{C}$, while the highest was at $31^{\circ} \mathrm{C}\left(0.84 \mathrm{mg} \mathrm{lit}^{-1}\right)$. One-way ANOVA test showed a significant temperature impact on average oxygen consumption rate of the post-larvae. The highest and lowest length and weight gains were observed at 29.5 and $31^{\circ} \mathrm{C}$, respectively with a medium growth at $28^{\circ} \mathrm{C}$. From the above, it may be concluded that the lethal/critical (maxima) temperature in shrimp thus, depend on acclimatizing temperatures, species, developmental stage and also

Author for Corresponding -

\section{PREETAM B. NAIK}

Department of Fisheries

Hydrography, College of

Fisheries, Shirgaon, RATNAGIRI

(M.S.) INDIA

See end of the article for

Coopted authors' other environmental variables.

KEY WORDS...... Growth, Oxygen consumption, Penaeus monodon, Post larvae, Temperature

HOW TO CITE THIS ARTICLE - Naik, Preetam B., Kulkarni, Girish N., Tekade, Ankita S. and Sadawarte, Rahul K. (2017). Response of post larvae of Penaeus monodon (Fabricius, 1798) to varying temperatures. Asian J. Animal Sci., 12(1): 56-60. DOI : 10.15740/HAS/TAJAS/12.1/56-60.

ARTICLE CHRONICLE - Received : 06.03.2017; Revised : 11.05.2017; Accepted : 24.05.2017 